\title{
ANALYSIS OF POST-TENSIONED BEAMS STRENGTHENED BY CFRP FOR FLEXURE
}

\author{
Roopa K.M. ${ }^{1}$, Jagannatha Reddy ${ }^{2}$ \\ ${ }^{1}$ Department of Civil Engineering, Bangalore Institute of Technology, Bengaluru-560001, Karnataka, India \\ ${ }^{2}$ Department of Civil Engineering, Bangalore Institute of Technology, Bengaluru-560001, Karnataka, India
}

\begin{abstract}
Pre-stressing is generally having more application in long span bridges. Repair or upgradation is done for Pre-stressed concrete structures to increase their load carrying capacity, stiffness to conquer the loss of Pre-stressing force due to construction and moving load. Since bridges cannot be reconstructed or replaced completely, repair and retrofitting is more suitable. In this experiment four number of Post-tensioned beams were cast to study the effect of Carbon Fiber Reinforced Polymer (CFRP) strengthened beams under flexural behavior. With different wrapping technique using CFRP Sheets parameters like deflection, ultimate load carrying capacity and pattern of cracking are also studied under static loading. CFRP were wrapped with full $U$ stripped for one beam, full U-Wrapping for one beam and another beam wrapped for soffit of beam by using technique called wetlay-up. Remaining one beam is considered as Control beam and compared with the strengthened beams. From the result of experimental work, it has shown that ultimate load carrying capacity and crack strength has been enhanced.
\end{abstract}

Keywords: CFRP, Flexure, Post-tensioned, Strengthening beams

\section{INTRODUCTION}

Pre-stressed concrete structures have more applications in long span bridges. PSC beams should be designed with proper codal provisions without which it leads to undesirable structural behavior like pre-stress loss in strands and less strength hierarchy and other causative aspects are deterioration of concrete and steel caused by environmental factors, change in usage, natural hazards such as earthquakes and cyclones and increase in loads leads to loss of strength, deflection, cracking, spalling etc. Since bridges cannot be reconstructed or replaced completely, repair and retrofitting is more suitable.

The most important regions in PSC beams are flexure and shear zones. Fiber Reinforced Polymer (FRP) technique can be used to strengthen these zones by retrofitting them externally. Retrofitting the FRPs strengthen the beams and this method provides an alternative to various traditional techniques like externally bonded steel plates, steel jackets, concrete jackets and external post tensioning.

Fiber reinforced material is a composite material which are made of carbon, aramid or glass fibers bonded with a polymeric matrix which may be epoxy polyester, vinyl ester etc. The polymeric matrix are resin used in FRP glues the concrete substrate and bundles the fibers together. By extensive research across the world has led to know the properties of FRPs and its behavior and is being used.

FRP materials are durable, non-corrosive high strength to weight ratio and exhibits high tensile strength. Since carbon fibers (CFRP Sheets) have high elastic modulus, high strength it is used as externally bonded reinforcement to resolve above problems. FRPs are found to be very effective for strengthening of existing structures because for having superior properties and high tensile strength, more than ten times of that of conventional steel. It is being used in the form of thin sheets, stripes, bars and tendons which are bonded externally to concrete structural members with epoxy coating by a process called wet lay-up which helps to increase their load carrying capacity.

In this paper, experimental investigation of 4 number of post-tensioned beams are presented to study the effect of CFRP strengthening material by wrapping externally to know the behaviour in flexure, cracking strength, deflection and ultimate load strength using different wrapping pattern by testing under static loading. Among 4 beams, one is control beam and remaining three beams are strengthened beams. CFRP were wrapped for full length with Uwrapping, U-strip wrapping, and at soffit of beams by process called wet lay-up.

The rest of the section is divided as follows: In order to get basis for present research work various researchers' works are reviewed as literature in section 2 . The materials used for present work are mentioned and discussed in section 3 . The details of experimental work includes testing, casting of beams and results are discussed in section 4. Results are discussed in section 5. Finally we conclude our paper.

\section{RELATED WORK}

The authors have conducted experimental work on flexural strengthening of post tensioned beams using FRP plates. The beam specimens used for this experiment were unbonded post-tensioned and bonded externally with Glass Fiber Reinforced polymer (GFRP) plates with different configurations and thickness of $3 \mathrm{~mm}$ and $5 \mathrm{~mm}$. The beams 
were tested under static loading up to failure and flexural behavior is examined. In this experiment the parameters included are ultimate load, ultimate deflection, and ductility failure mode and cracking pattern of the beams. [1]

In this experimental research work five beam specimens of $150 \mathrm{~mm} \times 250 \mathrm{~mm}$ and a length of $3000 \mathrm{~mm}$ were cast. The Pre-stressing force taken is equal to $75 \%$ of ultimate stress of Pre-stressing steel which was applied. The beam specimens were tested under two point loading and is gradually increased under static load condition. The GFRP strengthened beam exhibits increase in ultimate load carrying capacity by $16 \%$ and $35 \%, 65 \%$ and $89 \%$ respectively for $3 \mathrm{~mm}$ and $5 \mathrm{~mm}$ thickness plates compared to reference beam. The FRP strengthened unbonded posttensioned beams exhibits increase in cracked post-yielding stiffness compared to reference beam. Ductility has also been increased by $90 \%$ with FRP post tensioned beams. The unbonded PSC beam specimens was failed by yielding of bottom tension steel reinforcement later by crushing of concrete. The FRP strengthened PSC beam specimens fails by rupturing and debonding of FRP plates.

These authors [2] have studied the effect of relationships between structural damage and level of external prestressing force on flexural behavior of Pre-stressed concrete beams which is post tensioned under static cyclic loading. Their research work mainly focused on behavior of cracks, flexural moment capacity, deflection and flexural rigidity. The length of $6 \mathrm{~m}$, depth $0.55 \mathrm{~m}$, thickness $.1 \mathrm{~m}$, and width of flange $.8 \mathrm{~m}$ of PC T- beam has been casted. The Prestressing strands of diameter $12.7 \mathrm{~mm}$ and grade 270 i.e., ultimate strength of $1860 \mathrm{Mpa}$ were used as reinforcement for post tensioning. At transfer stage, the PC strands were stressed to $.75 \mathrm{Pu}$ to bond the strands into the surrounding concrete, the cement grout is filled into steel duct and these strands are placed in parabola shape. The static loading and unloading is performed in this test and load is applied through hydraulic hand pump. From the experimental results it showed that reduction in flexural rigidity and excessive deflection with the increase level of damage due to accumulation of cracks in Pre-stressed concrete structures and subjected to overloading. In service stage, deflection of girder due to high damage level exceeds the acceptable limit and due to this, high level damage reduces the proportional limit while permanent deformation increases.

The authors have conducted experimental study "on bond behavior between FRP reinforcement and concrete". Work has been done on flexurally strengthened real scale RC and pre stressed RC beams. In this work, some beams are bonded externally with FRP reinforcement in different modalities by using different types of end - anchorage devices and for some with transfer of Pre-stress. Four points bending tests are performed after the portrayal of single materials.

From the behavior of anchorages made both with the r-esin and by using different types of mechanical devices the failure and cracking modes are studied. From the experimental results it has been shown that on the basis of varying numerous parameter there is increase in ultimate capacity and also specifically by using mechanical anchored devices the delamination is delayed and increases ultimate capacity of structural element whereas CFRP pre tensioning reduces crack width and there is uniform distribution of cracks, enhances ultimate capacity of structural element and also there is increase in load at which first crack occurs and by utilizing CFRP material the strain values increases to ultimate. [3]

The authors in [4] have conducted experiment on CFRP strengthening of full scale PC girders on flexure. Experiment has been conducted on five I -shaped PSC girder of size $13000 \mathrm{~mm} \times 800 \mathrm{~mm}$ in which one is control beam and for four other beams concrete cover has been removed in order to simulate vehicle impact and also by differing percentage of tendons through cutting, they are damaged intentionally. The repair, for soffit girder the CFRP laminates by wet manual lay-up technique bonded externally and by wrapping technique, U- strips were wrapped at spacing of $150 \mathrm{~mm} \mathrm{c/c}$. Laminates anchoring system has been taken particular attention by restoring the ultimate flexural capacity of member. Experiment is focused on discussions with reference to control, strengthened CFRP and control specimens and also comparison of test results in terms of flexural capacity, deflections, strains and also modes of failure were presented. In the experimental study there is a decrease in flexural capacity to 20 and $26 \%$ due to loss of strands equal to 17 and $33 \%$ respectively. It is necessary to prevent fiber debonding to restore the ultimate flexural capacity of undamaged PSC specimens. By using cementitious mortar, perfect bond between existing concrete and girder restored zone should be guaranteed appropriately thus to increase potential effectiveness of strain in FRP in order to ensure benefits provided by $U$ wraps anchoring system. Both stiffness and flexural capacity of PSC damaged beams has been enhanced using CFRP laminates.

\section{MATERIAL PROPERTIES}

Table 1: Basic Properties of cement

\begin{tabular}{|l|l|}
\hline Properties & Obtained Values \\
\hline Specific gravity & 3.15 \\
\hline \multicolumn{2}{|l|}{ Setting time } \\
\multicolumn{1}{l|}{$\quad$ Initial } & $100 \mathrm{~min}$ \\
$-\quad \quad$ Final & $210 \mathrm{~min}$ \\
\hline Fineness & $5 \%$ \\
\hline Soundness & $1 \mathrm{~mm}$ \\
\hline
\end{tabular}

Table 2: Basic Properties of aggregates

\begin{tabular}{|l|l|l|}
\hline Particular & Fine aggregate & coarse aggregate \\
\hline Specific gravity & 2.62 & 2.72 \\
\hline Water absorption & $1.2 \%$ & $0.6 \%$ \\
\hline Fineness modulus & 3.281 & - \\
\hline zone & II & - \\
\hline
\end{tabular}


Table 3: High tensile steel properties

\begin{tabular}{|l|l|}
\hline Properties & Spring Steel (Grade III) \\
\hline Strand diameter & $12.7 \mathrm{~mm} 7$ ply \\
\hline Cross sectional Area of strand & $98.7 \mathrm{~N} / \mathrm{mm}^{2}$ \\
\hline Ultimate Tensile Strength & $1960 \mathrm{~N} / \mathrm{mm}^{2}$ \\
\hline Nominal Mass & $0.775 \mathrm{~kg} / \mathrm{m}$ \\
\hline
\end{tabular}

Table 4: Properties of Nitowrap Carbon Fiber sheets

\begin{tabular}{|l|l|}
\hline Nominal Thickness $(\mathrm{mm})$ & 0.3 \\
\hline Nominal Width $(\mathrm{mm})$ & 500 \\
\hline Tensile Strength $\left(\mathrm{N} / \mathrm{mm}^{2}\right)$ & 3500 \\
\hline Young's Modulus $\left(\mathrm{N} / \mathrm{mm}^{2}\right)$ & 285000 \\
\hline Elongation $(\%)$ & 1.5 \\
\hline
\end{tabular}

Mix proportion for M40 grade concrete per $\mathrm{m}^{3}$ Cement $=420 \mathrm{~kg} / \mathrm{m}^{3}$

Fine aggregate $=774 \mathrm{~kg} / \mathrm{m}^{3}$

Coarse aggregate $=1091 \mathrm{~kg} / \mathrm{m}^{3}$

Water $=168$ liters

$\mathrm{W} / \mathrm{C}$ ratio $=0.40$

\section{EXPERIMENTAL PROGRAME}

The main objective of experiment is to study behavior of post tensioned control beam and to compare stiffness, ultimate flexural capacity and pattern of cracking with the flexure strengthened post tensioned beams using CFRP sheets and to carry out experiment four beams of same size are cast.

After 28 days curing, four beams were tested under two point loading under pure bending condition and beams were divided into two groups of four numbers i.e., three strengthened beams and one control beam [fig. 1]

a) Controlled post tensioned beam/unstrengthened beam $[\mathrm{CB}\}$

b) Beam strengthened with full bottom wrapping by CFRP sheets[SB-1]

c) Beam strengthened with full U-wrapping by CFRP sheets[SB-2]

d) Beam strengthened with U-strip wrapping by CFRP sheets[SB-3]

$3.4 \mathrm{~m}$

\section{IIIIIIIIIIII | osm}

$3.4 \mathrm{~m}$

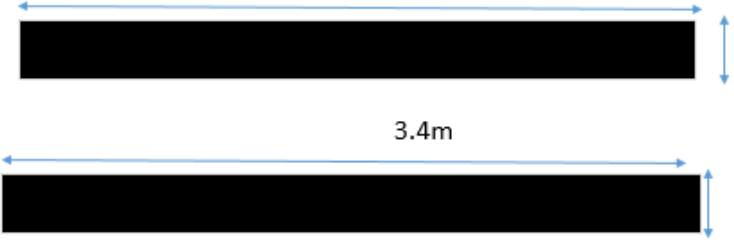

Fig 1 Schematic diagram of wrapping technique
The beam dimension as per design is taken as width of 230 $\mathrm{mm}$, height of $300 \mathrm{~mm}$ and $3400 \mathrm{~mm}$ long. 2 bars of $12 \mathrm{~mm}$ diameter were provided as bottom reinforcement and $10 \mathrm{~mm}$ diameter of 2 bars were provided as top reinforcement and along the length of beam 2 legged 8mm diameter stirrups were provided with spacing of $200 \mathrm{~mm} \mathrm{c/c}$. To fail in flexure zone, shear zone is strengthened by providing stirrups.7 ply of $12.7 \mathrm{~mm}$ diameter high tensile wires were provided of two number with $106 \mathrm{~mm}$ eccentricity from bottom. For tendons a total force of $170 \mathrm{kN}$ was applied. Reinforcement and their details are shown in fig 2.
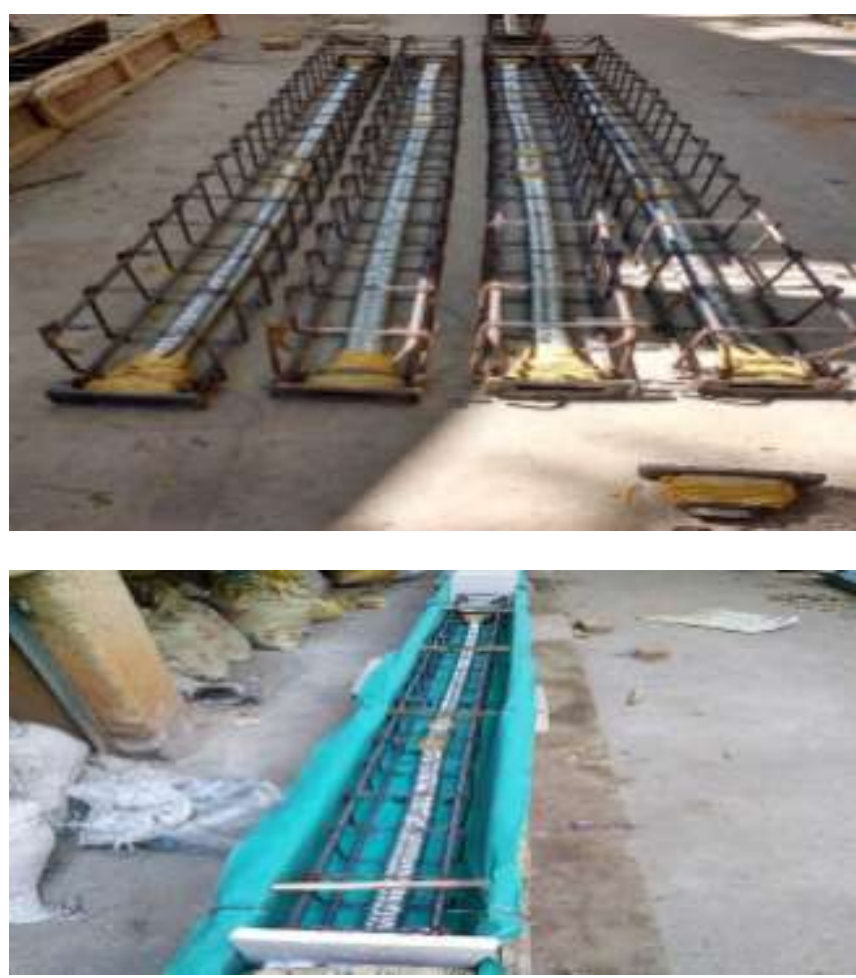

Fig 2 Reinforcement and its cage

\subsection{Casting of Beams}

For casting beams, moulds of size 230 X 300 X 3400mm are prepared and inside of moulds is oiled in order to remove beams easily after hardening. With the above mentioned reinforcement details, the reinforcement cage is prepared and inside the cage sheathing duct is positioned properly. As sheathing duct is restricted with $2.5 \mathrm{~m}$ size, couplers were used to join the two sheathing ducts. To avoid entering of concrete in duct, cone was placed at two ends by covering face. Mixing of concrete is done with the help of machine mixer to get uniform quality of concrete. Then by using needle vibrator, proper compaction is done and concrete surface is levelled and smoothened by using trowel. Beams are removed from moulds after 24 hours. Curing is done to prevent loss of water in concrete which is necessary for hydration process and hardening. Gunny bags are covered on surface of beams and by spraying water curing is done for a period of 28 days.

\subsection{Post-Tensioning of Beams}

After beams attains its sufficient strength, they are stressed. For post -tensioning, 2 numbers of $12.7 \mathrm{~mm}$ diameter 
tendons were placed in sheething duct. By using wedges and barrels, one end of tendons are anchored and force was applied at other end. Force was applied of about $70 \%$ of ultimate strength of steel $\left(520 \mathrm{~kg} / \mathrm{cm}^{2}\right)$ [Fig. 3].

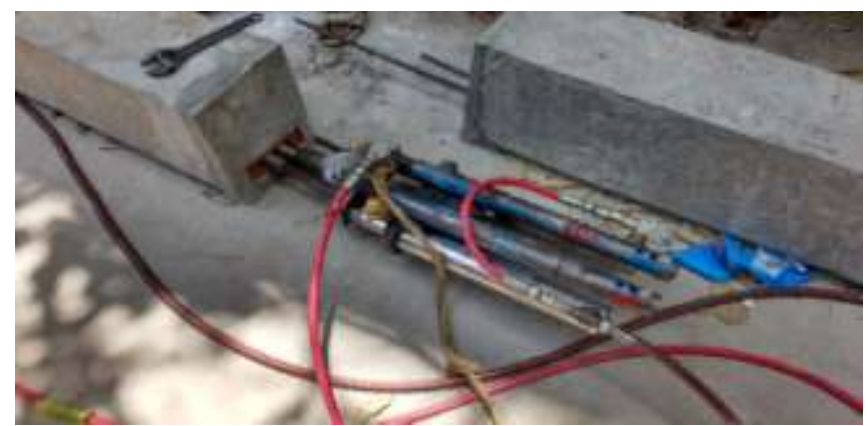

Fig 3 Post-tensioning Operation

\subsection{Strengthening of Beams by CFRP Wrapping}

Among four beams, one beam was used as control beam, three beams strengthened by CFRP with U-full wrapping, U-strip and full length bottom wrapping as shown in fig 4 .

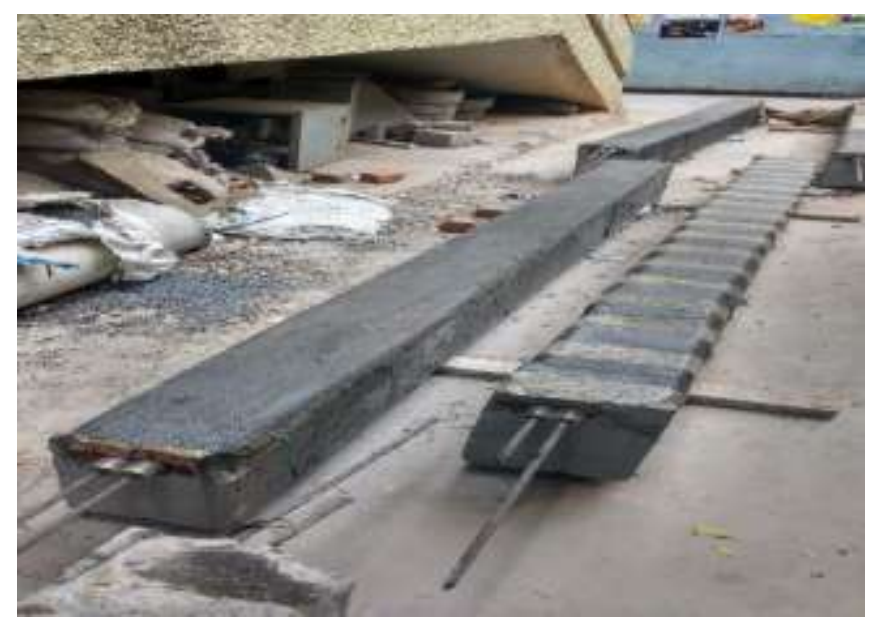

Fig 4 Strengthened beams

\subsection{Surface Preparation and CFRP Wrapping}

Before installing FRP sheets, the corners of beams were rounded of about $15 \mathrm{~m}$ radius at wrapping positions. To open pore textures, concrete surface was prepared using water blasting and is allowed to dry before FRP application. Cracks, spalls, reinforcing steel should be cleaned and cracks more than $0.25 \mathrm{~mm}$ width should be injected with epoxy and surface should be cleared with loose material.

By using nap short roller, epoxy based primer (Nitowrap 30 base $\&$ hardener of ratio $1: 10$ ) is coated by layer on prepared concrete surface. The primer is done to cover the concrete pores and to improve adhesive bonding for saturant resin. To cover with small holes, thin layer of putty which is thick epoxy based paste was applied by using trowel after primer becomes tack-free.

After putty becomes tack-free, first coat of saturant resin (Nitowrap 410 base and hardener) is applied using nap roller. Saturant resin is applied to saturate the dry fibers and to maintain fibers in required direction, to protect fibers from adverse environmental effects and also to distribute stress to fibers.

Before installing CFRP sheets on surface, they were measured and cut by blade for desired requirement. Sheets are placed on surface of concrete in desired orientation by pressing gently on saturant and air bubbles are removed by using trowel.

The second layer of saturant resin was coated on sheet and resin if excess are removed.

\subsection{Testing of Beams}

The beams were analyzed by loading at 2 points. Analysis is done by using loading frame of capacity 100 ton and hydraulic jack of capacity $1000 \mathrm{~kg}$. Beams are kept to have effective span of $3 \mathrm{~m}$ between supports and by making 3 equal parts load was applied at points of divided length. To distribute load over width of beam, steel rods were used under loads. The set up make sure that pure bending in the central portion of beam. To make attachments in contact with each other, initially a small amount of load was applied after beam set up is done. Below the loading point and at the center three dial gauges were placed. Deflections were noted with the corresponding load and observed crack and its width were recorded. The load is released slowly after load is applied up to ultimate. Loading arrangement is done as shown in fig 5 .

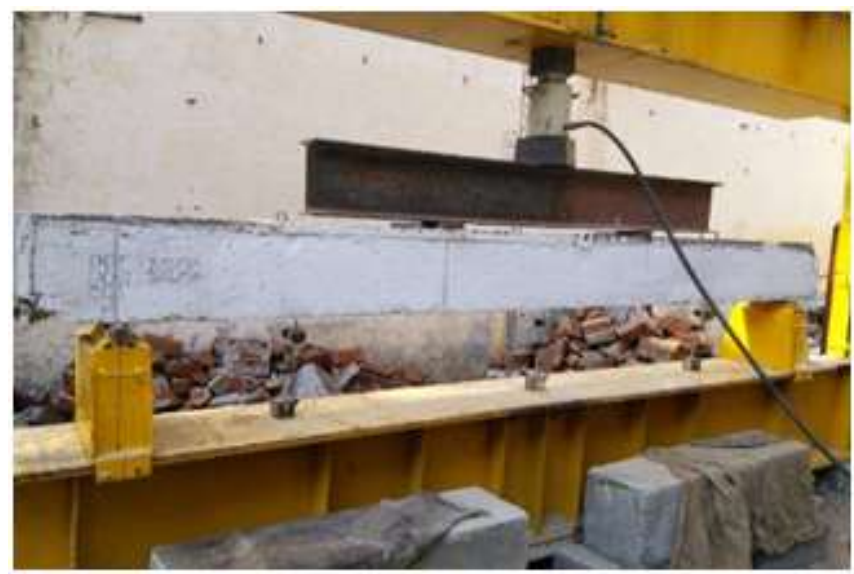

Fig 5 Experimental set up

\section{RESULTS AND DISCUSSIONS}

Results of Experiments conducted on four post-tensioned beams which is unbonded and includes of one control beam, one beam strengthened with bottom wrapping by CFRP sheets, one beam strengthened with U-bottom wrapping by CFRP sheets, and last one beam strengthened with full Uwrapping by CFRP sheets are presented. The deflection and cracking are measured and compared with control beam.

\subsection{Control Beam}

Post-tensioned unstrengthened or control beam has been loaded in a setup of two point loading as discussed above. The effective span of $3 \mathrm{~m}$ is divided into two equal parts and has been loaded with equal force on two points until beam fails. Deflections are noted for corresponding load. For load 
of $56 \mathrm{kN}$ the first crack which is minor flexure crack was observed with crack width of $0.06 \mathrm{~mm}$. Cracks are initiated from bottom and number of cracks increased with increase in load. Second and third cracks were observed after primary cracks and all cracks appeared vertically and sub cracks were originated by connecting to main cracks. Deflection@ @ultimate found to be $22.783 \mathrm{~mm}$. The plot has been done for load deflection as shown in fig. 6.Before failure, the beam undergoes large deflection. The observed deflection at first crack and ultimate load is $4.102 \mathrm{~mm}$ and $118 \mathrm{kN}$ respectively.

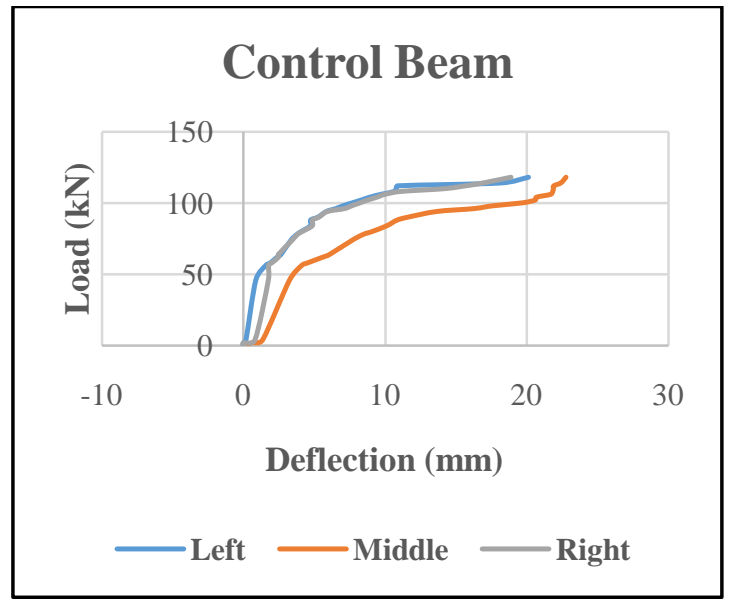

Fig 6 Load v/s deflection for CB

Beam was strengthened by CFRP sheets to examine flexural behavior and hence beam was strengthened in flexure zone i.e. full length of beam is wrapped with CFRP sheets. The first crack which is minor crack was observed at $96 \mathrm{kN}$ and ultimate load reaches at $172 \mathrm{kN}$.As beam is strengthened in soffit of beam the propagation of cracks are minimized and crack width is also reduced compared to control beam. CFRP sheets prevents development and widening of cracks. At a load of $170 \mathrm{kN}$, debonding of sheets was occurred without splitting of concrete. The plot has been done for load deflection as shown in fig. 7 and before failure beam gives minimum deflection. When compared with unstrengthened beam load carrying capacity has been increased by $45.76 \%$. Even though full debonding of CFRP sheets occurs at $170 \mathrm{kN}$, in order to get failure load, load has been increased till complete failure of beam.

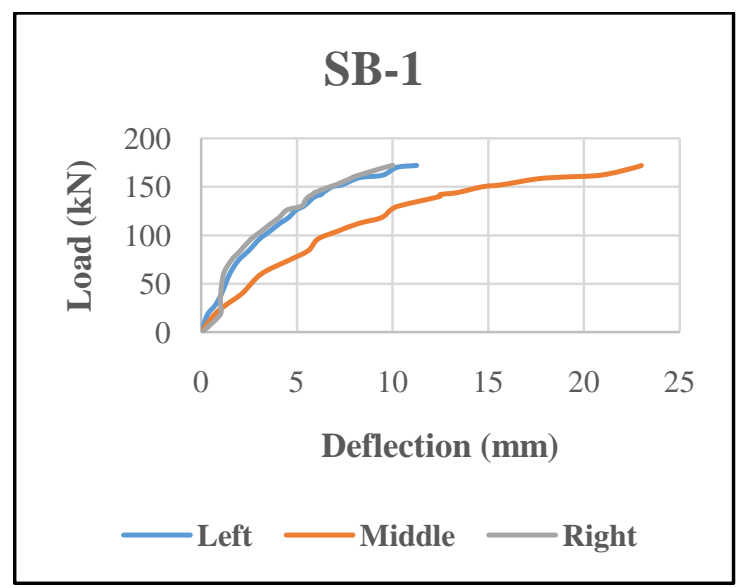

Fig 7 Load v/s deflection for SB-1
The beam was strengthened by CFRP sheets providing full U-strip wrapping. The first crack appeared at $84 \mathrm{kN}$ and 180 $\mathrm{kN}$ is the ultimate load where beam fails in flexure. The propagation of cracks and crack width were decreased in strengthened beams compared to control beams. The capacity in flexure has been increased up to $52.54 \%$ compared to control beam. The load deflection behavior has been plotted as shown in fig. 8 .

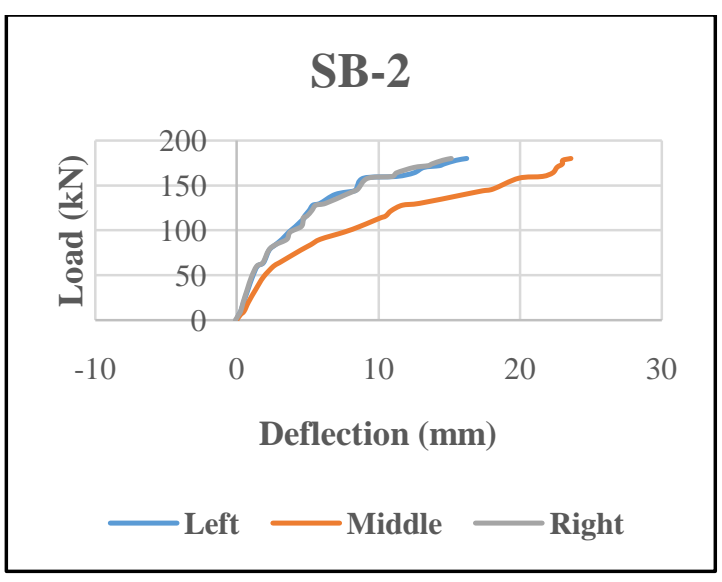

Fig 8 Load v/s deflection for SB-2

Beam was strengthened by CFRP sheets providing full Uwrapping. Since beam was wrapped fully the cracks were restricted and debonding of sheets occurred at load of 148 $\mathrm{kN}$ and $180 \mathrm{kN}$ is the ultimate load. Eventhough full debonding of sheets occurred at $148 \mathrm{kN}$, load has been increased to get failure load. [fig 9]

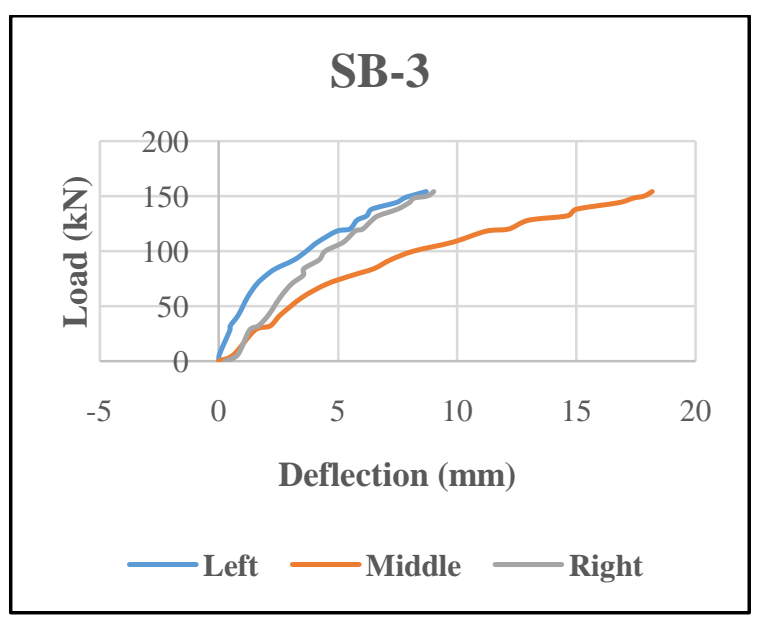

Fig 9 Load v/s deflection for SB-3

\subsection{Comparison between Control Beam and}

\section{Strengthened Beams}

The curves of load v/s deflection [fig. 10] for both control and retrofitted beams are shown above and from the curves it has shown that strengthening beams such as SB-1, SB-2, and SB-3 increases their load carrying capacity when compared to control beam i.e. CB. Strengthening beam designated as SB-3 curve has a maximum load of $180 \mathrm{kN}$ which is $52.54 \%$ higher than control beam, SB-2 curve has maximum load of $180 \mathrm{kN}$ which is more than control beam 
of $52.54 \%$ and SB-1 curve has a maximum load of $172 \mathrm{kN}$ which is higher than control beam of $45.76 \%$. The results of all the beams are presented in table 5 .

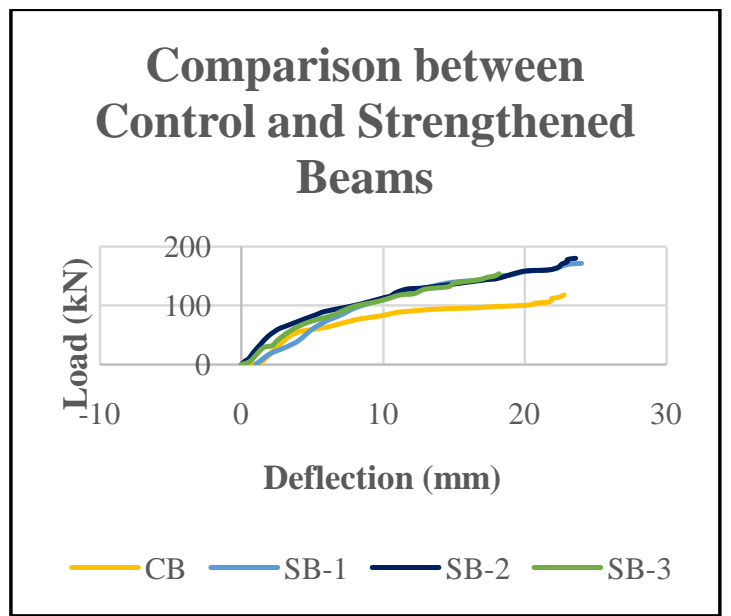

Fig 10.Comparison of control and strengthened beams by centre deflection

Table 5 Results of all beams

\begin{tabular}{|l|l|l|l|l|}
\hline $\begin{array}{l}\text { Beam } \\
\text { specimens }\end{array}$ & $\begin{array}{l}\text { Load } \\
\text { at first } \\
\text { crack } \\
\mathbf{( k N )}\end{array}$ & $\begin{array}{l}\text { Ultimate } \\
\text { load } \\
(\mathbf{k N})\end{array}$ & $\begin{array}{l}\text { Deflection } \\
\text { at ultimate } \\
\text { load }(\mathbf{m m})\end{array}$ & $\begin{array}{l}\text { Crack } \\
\text { width at } \\
\text { service } \\
\text { load } \\
(\mathbf{m m})\end{array}$ \\
\hline CB & 56 & 118 & 22.783 & 0.41 \\
\hline SB-1 & 96 & 172 & 22.692 & 0.25 \\
\hline SB-2 & 84 & 180 & 22.989 & 0.2 \\
\hline SB-3 & $\begin{array}{l}\text { Debonding at load of } 148 \mathrm{kN} \text { and ultimate } \\
\text { load of } 180 \mathrm{kN}\end{array}$ \\
\hline
\end{tabular}

\subsection{Failure Modes of Crack Pattern}

In control beam, the first crack observed at a load of $56 \mathrm{kN}$ in middle portion of beam and cracks are further propagated with increase in load up to top portion of beam and as load is increased new cracks were formed in the zone of shear and flexure. It was observed that 13 cracks were appeared in central region experienced failure in flexure as shown in fig 11 .

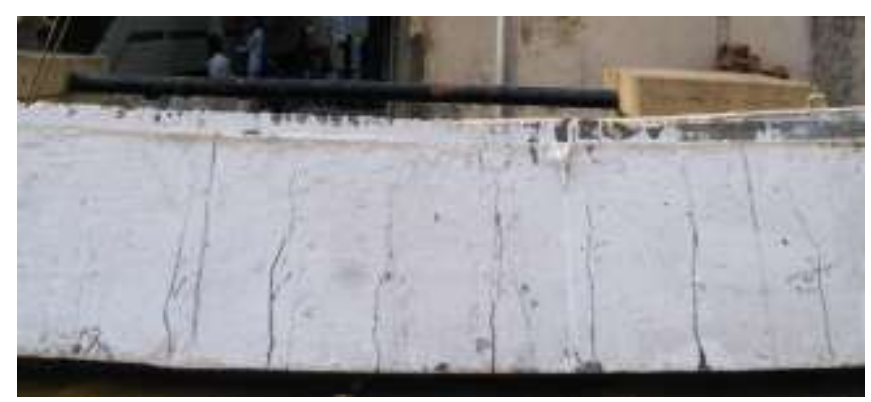

Fig 11.Crack pattern in control beam

In SB-1 beam, the first crack appeared at $96 \mathrm{kN}$ and number of cracks observed are 10.The cracks which was appeared initially were same as control beam and cracks were increased in length with increase in load since beam were strengthened at bottom, compared to control beam its width were reduced. Debonding of sheets was occurred at $170 \mathrm{kN}$ as shown in fig 12.

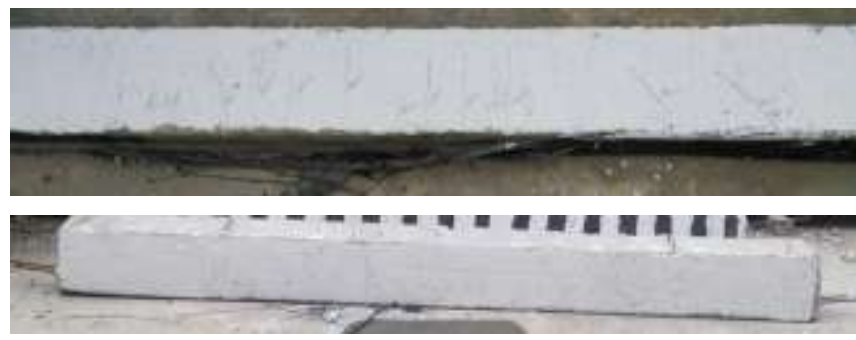

Fig 12. Crack pattern and debonding occurred in SB-1 beam

In SB-2 beam, first crack appeared at $84 \mathrm{kN}$ and cracks observed were 9.Since beam is strengthened with CFRP sheets in U-strip, crack width is smaller in space between the sheets compared to control beam. Cracks in epoxy was found at $110 \mathrm{kN}$ and beam failed in flexure as shown in fig 13.

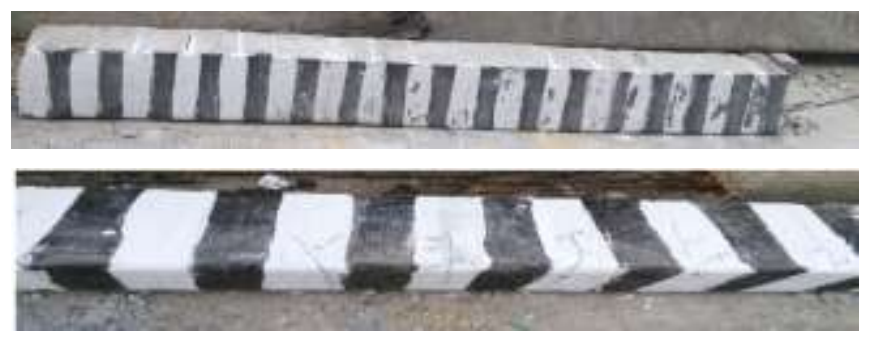

Fig 13. Crack pattern in SB-2 beam

In SB-3 beam, cracks in epoxy found at $108 \mathrm{kN}$ and debonding of sheets occurred at $148 \mathrm{kN}$ [Fig 14].

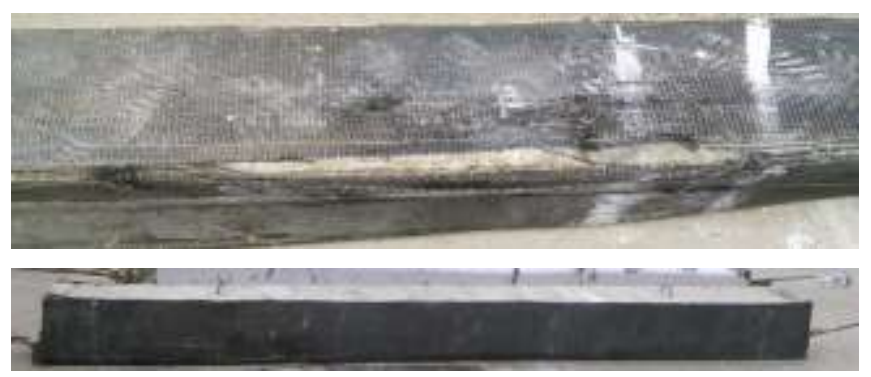

Fig 14.Crack pattern and full debonding occurred in SB-3 beam.

\section{CONCLUSION}

Based on results and observation of experimental study some conclusion can be drawn as follows:

1) The ultimate load carrying capacity of CFRP strengthened beam with pattern of U-Stripped and full U-Wrap was found to be $52.54 \%$ more than that of control beam.

2) Beam with bottom wrapping have been carried out 45.76\% ultimate strength more than control beam.

3) The structural response of strengthened beam is more effective in terms of width of crack than control beam.

4) The number of cracks found in strengthened beams is minimum than control beam. 
5) Comparing beam which is strengthened with different wrapping technique, beam strengthened with pattern of U-Full wrap and U-Strip wrap were more effective in load carrying capacity.

6) From the results the main failure mode was by sheets debonding which decreases the efficiency of strengthening. So, it can be concluded that anchorage is a solution to avoid debonding.

7) Provided strengthening for soffit i.e., bottom wrapping moderately increases the flexural capacity. So, it can be concluded that other wrapping technique i.e., full UWrapping and U-Stripped wrapping are better solution.

\section{REFERENCES}

[1]. Revathy J. and Sriraman M., "Structural Response of FRP Strengthened Post-TensionedConcrete Beams" Research Journal of Recent Sciences, Vol. III (2014)

[2]. Thananun Phuwadolpaisarn, sayan sirimontree, "Relations between structural damage andlevel of external pre-stressing force on flexural behaviour of post-tensioned, pre-stressedconcrete beams", international transaction journal of engineering, (2013).

[3]. C.Pellegrino \& C. Modena,'Flexural behaviour of RC and PC beams strengthened withexternal pretension FRP laminates", Department of constructions and transportationengineering, padova university, 2012.

[4]. M.Di Ludovico, A.prota, G.Manfredi and E.cosenza,"FRP strengthening of Full-scale PCgirders", journal of composites for construction volume 14,October 2010.

[5]. IS: 456-2000, Plain and Reinforced concrete- Code of Practice, Bureau of IndianStandards, New Delhi

[6]. IS: 10262-2009, Concrete Mix ProportioningGuidelines, Bureau of Indian Standards,NewDelhi

[7]. IS: 1343-1980, Code of practice for Pre stressed Concrete, Bureau of Indian Standards, NewDelhi

[8]. IS: 6006-1983, Specification for Uncoated stress relieved strand for Pre stressed Concrete,Bureau of Indian Standards, New Delhi

[9]. IS: 383-1997, Specification for Coarse and Fine aggregates from Natural Sources forConcrete, Bureau of Indian Standards, New Delhi. 